\title{
The rodent model of irritable aggression: A method for analyses of individual roles in paired fighting*
}

\author{
WILLIAM B. GHISELLI and DONALD H. THOR \\ Research Department, Edward R. Johnstone Training and Research Center, Bordentown, New Jersey 08505
}

\begin{abstract}
Ten pairs of Long-Evans male rats were selected for reliable fighting to footshock. For each pair, one member (on Day 1), and the other member (on Day 2), was temporarily rendered docile by local anesthesia of the vibrissal pad. Attack scores decreased significantly $(\mathrm{p}<.0001)$ when one member was anesthetized, but component elements of the score varied in direction. Biting increased $(p<.001)$ and boxing decreased $(p<.0001)$. Upright and supine posturing mean differences were nonsignificant. The results suggest an inherent ambiguity in standard observational measures of paired fighting behavior. The present method has evident potential for discriminating nonapparent dominance relationships in normally fighting pairs and for stabilizing aggressor-target roles in the shock-elicited aggression paradigm.
\end{abstract}

Aggressive behavior in animals may be characterized as under the stimulus control of social cues resulting from the behavioral interaction of the participants. In the simplest case of only two protagonists, one method for determining the relative influence of an individual has been to render a single animal docile. In the context of irritable aggression between paired rats, Ulrich and Azrin (1962) shocked one member of a pair by implanted dermal electrodes and reported that less fighting occurred than when both animals received simultaneous shock. Insulating the rear feet of a dangling target rat resulted in extremely low levels of attack by a freely moving footshocked rat (Knutson, 1971). When one member of a pair is treated with chlorpromazine, the nontreated member exhibits a dose-related suppression of footshock-elicited attack behavior (Powell, Francis, Bramin, \& Schneiderman, 1969), and when a nonshocked male target is replaced with a receptive female target, a low level of attack by a tail-shocked rat is supplanted by copulation (Caggiula, 1972). In general, manipulations that decrease fighting when applied to both members also decrease fighting when applied to a single member; the normally aggressive behavior of a nontreated $\mathrm{S}$ appears, under stimulus control, determined by one or more specific cues in the behavior of his opponent.

Local anesthesia of the vibrissal pad markedly reduces shock-elicited fighting in paired rats when applied to both members (Thor \& Ghiselli, 1973). However, informal observation indicates that when one member of a pair is facially anesthetized, the untreated member appears to increase intensity of attack with a higher incidence of biting. Unlike insulated or chlorpromazine-treated target Ss, the facially anesthetized target $\mathrm{S}$ reacts normally to footshock. Consequently, the typical rapid and gross body movement of the target S immediately following shock may be related to probability of attack by the nontreated member of the pair.

*Supported by National Institute of Mental Health Research Grant MH 21577-02. Reprints may be obtained from either author.
The present study was undertaken to quantify previous informal observations in reference to biting attack upon an opponent rendered docile by facial anesthesia. Major components of a standard observational definition of shock-elicited fighting (Eichelman, 1971) were recorded to measure any gross change in the quality of fighting. Criteria for specification of occurrence or nonoccurrence of fighting have historically been generic in terms of movements with emphases upon a stereotypical upright and mutually facing posture (Ulrich, 1966, pp. 644-645). Recent innovative techniques for automated recording are derivative of the classical definitions (Selekman \& Meehan, 1974), but do not uniformly demonstrate correlative measures related to observed incidence of fighting (Thor, Ghiselli, \& Wilson, 1973).

\section{METHOD}

\section{Subjects}

Ten pairs of laboratory-reared 180-day-old male Long-Evans rats were selected for reliable shock-elicited aggression. Each pair had been tested on 14 preliminary sessions and fought after at least $70 \%$ of the shocks on the final 3 sessions. Pairs were noncagemates originally formed on the basis of comparable weight. Ss were all socially housed (pairs) in rack-mounted wire cages with ad lib food and water, to which a broad spectrum antibiotic had been added.
Apparatus
The apparatus consisted of a standard rodent operant chamber with a grid floor to which timed intervals of neon-scrambled, constant-current shock were delivered.

\section{Procedure}
Immediately prior to lidocaine testing, each pair received three daily tests for shock-elicited fighting to establish baseline fighting levels. On two subsequent daily test sessions, on the first day (Day 1) one member, and on the second day (Day 2) the other member, of each pair received bilateral $0.2-\mathrm{ml}$ subcutaneous injections of $1 \%$ lidocaine $\mathrm{HCl}$ in the area of the mystacial vibrissae following light ether anesthesia. Thirty minutes after injections, the Ss were tested for shock-elicited aggression. A test session consisted of $502.0-\mathrm{mA}, 0.5$-sec shock: delivered at 3.0 -sec intervals. Criteria for attack, described by Eichelman (1971), required directed movement by at least one 
Table 1

Mean Percentage of Shocks Eliciting Fighting-Related Behaviors

\begin{tabular}{lrrrrr}
\hline & \multicolumn{2}{c}{ Baseline } & & \multicolumn{2}{c}{ Lidocaine } \\
\cline { 2 - 3 } \multicolumn{1}{c}{ Behavior } & Mean & SE & & Mean & SE \\
\hline Attack* & 82.4 & 2.4 & & 46.4 & 4.1 \\
Boxing & 74.3 & 2.7 & & 22.3 & 3.0 \\
Biting & 9.0 & 1.7 & & 26.8 & 4.0 \\
Supine Posture & 9.7 & 2.2 & & 9.1 & 1.8 \\
Upright Posture & 9.0 & 2.1 & & 4.4 & 0.6 \\
\hline
\end{tabular}

*By definition inclusive of the boxing, biting, supine, and upright measures.

rat toward the other, resulting in physical contact and followed by one or more of four behaviors: mutual upright boxing, upright facing posture without physical contact, supine posture by at least one rat, or a quick or prolonged biting strike at the opponent's snout. Fighting was expressed as the percent of shocks effective in eliciting attack. Additionally, the percent of shocks effective in eliciting each of the behavioral categories comprising attack was noted.

\section{RESULTS}

Measures for individual pairs were averaged within the lidocaine and baseline conditions. Group means and standard errors are presented in Table 1.

Giving lidocaine to one member of the pair significantly reduced the general attack score $(t=9.31$, $\mathrm{df}=9, \mathrm{p}<.0001)$. However, considering the individual behavioral components of shock-elicited attack (Table 1), it may be seen that this decrement reflected a significant drop in boxing $(\mathrm{t}=14.06, \mathrm{df}=9, \mathrm{p}<.0001)$ while masking a significant increase in biting $(t=5.54$, $\mathrm{df}=9, \mathrm{p}<.001)$. No significant changes occurred in the upright or supine posture measures, nor were any order effects of lidocaine (Day 1 vs Day 2) detected on any of the component measures or the overall fight score (all ts, two-tailed).

The anesthetized member of a pair rarely initiated directed movement toward the opponent, but engaged in boxing and attempted to escape (i.e., turned away) from the unanesthetized opponent. Further, the magnitude of the drop in the overall attack score in the lidocaine condition depended upon which individual received lidocaine. When the fight score on Day 1 was subtracted from that on Day 2, the absolute difference ranged from 10 to 70 percentage points and averaged 30.4 points. The intensity of biting was unquestionably greater under lidocaine, with frequent sustained contact of the lidocaine-treated animal's snout by the unanesthetized opponent. In such cases, severe wounds sometimes occurred, an event not normally seen in shock-elicited fighting.

\section{DISCUSSION}

Facial anesthesia to one member of a pair of shocked rats increased biting attack by the nontreated member and decreased mutual boxing or sparring behavior. Although the anesthetized member was quite docile (compared to the nonanesthetized state), his untreated opponent fought vigorously, with numerous and sometimes prolonged biting attacks directed to his opponent's snout. Anesthesia of the vibrissae appears to be an exception to the generalization that enforced docility of an opponent decreases attack behavior in the other member of the pair following momentary footshock.

The results suggest an ambiguity in the measurement of fighting. If boxing is taken as the criterion (Ulrich, 1966), a decrease in fighting occurred when lidocaine was administered to one member of the pair. However, if biting is taken as the appropriate measure (Azrin, Rubin, \& Hutchinson, 1968), an increase in fighting occurred. This problem of defining the behaviors which constitute "aggression" in rodents is not new, and the definition may change with differing strains and aggressive histories (Kimbrell, 1968; Reynierse, 1971). For example, Reynierse (1971) has described the shock-elicited fighting behavior of naive albino rats as "a low intensity mood which becomes increasingly less descriptive of laboratory rat behaviour with additional shock trials [p. 106]," and characterized it as increasingly more submissive. Naive hooded rats also show a decreasing amount of fighting within the initial test session (unpublished observations); however, with additional sessions, aggressive behavior increases to high and stable levels. Variables initially effective in modifying attack may also vary with aggressive experience (Thor \& Ghiselli, 1974). The differential depression in fighting depending upon which member of a pair was rendered docile indicates that just as the nonaggressive behavior of one rat can lower fighting (Powell et al, 1969), the attack behavior of one member can maintain it. This may be seen in the behavior of one pair, which fought $75 \%$ at baseline, $70 \%$ when Member A was anesthetized, and $0 \%$ when Member B was anesthetized.

The present results indicate that generic definitions of shock-elicited aggression are inadequate for describing the alterations in fighting produced by rendering one member docile. Kršiak and Steinberg (1969) have described a similar problem in assessing the change in aggression occurring when a colony of mice are rendered docile by drugs and an undrugged intruder is introduced. Their generic measure showed no difference in aggression between drugged and undrugged colonies, while individual behaviors showed marked drug-induced changes in social, flight, and aggressive acts.

Beach (1956) has described a general approach to the experimental analysis of species-typical behavior, which offers guidelines as to which acts do and which do not characterize the behavior. Grant and MacKintosh (1963) have proposed an initial set of acts which may be used to describe aggressive behavior in rodents. A combination of such approaches may be useful in clarifying a behavioral definition of rodent aggression.

The present method of rendering individual rats docile appears to leave shock sensitivity unaltered and offers a new method for revealing dominance relationships between paired rats and for structuring experimental situations in terms of stable aggressor and target roles (normal vs anesthetized Ss, respectively).

\section{REFERENCES}

Azrin, N. H., Rubin, H. B., \& Hutchinson, R. R. Biting attack by rats in response to aversive shock. Journal of the Experimental Analy sis of Behavior, 1968, 11,633-639.

Beach, F. A. Characteristics of masculine "sex drive." In M. R. Jones (Ed.), Nebraska symposium on motivation. Vol. 4. Lincoln: University of Nebraska Press, 1956. Pp. 1-41.

Caggiula, A. R. Shock-elicited copulation and aggression in male rats. Journal of Comparative \& Physiological Psychology, 1972, 80, 393-397.

Eichelman, B. S. Effects of subcortical lesions on shock-induced aggression. Journal of Comparative \& Physiological Psychology, 1971, 74, 331-339. 
Grant, E. C., \& MacKintosh, J. H. A comparison of the social postures of some common laboratory rodents. Behaviour $1963,21,246-259$

Kimbrell, G. M. "Fighting response": A definitional problem. Psychological Record, 1968, 18, 639-640.

Knutson, J. F. The effects of shocking one member of a pair of rats. Psychonomic Science, 1971, 22, 265-266.

Kršiak, M., \& Steinberg, H. Psychopharmacological aspects of aggression: A review of the literature and some new experiments. Journal of Psychosomatic Research, 1969, 13, 243-252.

Powell, D. A., Francis, J., Bramin, M. J., \& Schneiderman, N. Frequency of attack in shock-elicited aggression as a function of the performance of individual rats. Journal of the Experimental Analysis of Behavior, 1969, 12, 817-823.

Reynierse, J. H. Submissive postures during shock-elicited aggression. Animal Behaviour, 1971, 19, 102-107.

Selekman, W., \& Meehan, E. An objective technique for recording shock-induced aggression in unrestrained pairs of rats. Journal of the Experimental Analysis of Behavior, 1974, 21, 177-180.
Thor, D. H., \& Ghiselli, W. B. Prolonged suppression of irritable aggression in rats by facial anesthesia. Psychological Reports, $1973,33,815-820$.

Thor, D. H., \& Ghiselli, W. B. Visual and social determinants of shock-elicited aggressive responding in rats. Animal Learning \& Behavior, 1974, 2, 74-76.

Thor, D. H., Ghiselli, W. B., \& Wilson, L. D. Vocalization as an objective measures of shock-elicited social aggression in rats. Animal Learning \& Behavior, 1973, 1, 263-267.

Ulrich, R. Pain as a cause of aggression. American Zoologist, $1966,6,643-662$.

Ulrich, R. E., \& Azrin, N. H. Reflexive fighting in response to aversive stimulation. Journal of the Experimental Analysis of Behavior, 1962, 5, 511-520.

(Received for publication March 27, 1974.)

\title{
Semantic factors in intentional and incidental sentence recall
}

\author{
SHELDON ROSENBERG*, WILLIAM J. SCHILLER, and JOAN A. SMITH \\ University of Illinois at Chicago Circle, Chicago, Ilinois 60680
}

\begin{abstract}
Independent groups were exposed to normal or anomalous sentences under an incidental-nonsemantic (letter estimation), incidental-semantic (familiarity rating), or intentional-only orientation. Written recall followed one presentation of the sentences in each group. None of the differences between intentional and incidental-semantic Ss was significant, and semantic coding facilitated recall performance for both normal and anomalous sentences but to a greater extent for normal sentences.
\end{abstract}

Rosenberg and Schiller (1971) found that when

*Requests for reprints should be sent to Sheldon Rosenberg, Department of Psychology, University of Illinois at Chicago Circle, Box 4348, Chicago, Illinois 60680. incidental Ss were given an orienting task that was designed to lead them to encode sentences semantically, their recall performance did not differ from the recall performance of $\mathrm{Ss}$ given intentional learning 